\title{
PREDICTORS OF PREGNANCY RELATED COMPLICATIONS IN WOMEN WITH HEART DISEASE
}

\author{
Sapna $S^{1}$, Asha P. S
}

${ }_{1}^{1}$ Assistant Professor, Department of Obstetrics and Gynaecology, T. D. Medical College, Alappuzha, Kerala. ${ }^{2}$ Assistant Professor, Department of Obstetrics and Gynaecology, T. D. Medical College, Alappuzha, Kerala.

\section{BACKGROUND}

ABSTRACT

The outcome of pregnancies in 100 women with heart disease, both congenital and acquired who received their obstetric care at Medical College Hospital, Kottayam, was evaluated. The aim of the study was to comprehend the impact of heart disease during pregnancy, to study the cardiac complications in pregnant women with heart disease, to identify predictors of pregnancy related cardiac complications in women with heart disease, to assess the individual risk of each pregnant woman with heart disease.

\section{MATERIALS AND METHODS}

In this retrospective cohort study, the outcome of pregnancies in 100 women with heart disease who received their obstetrical care at Medical College Hospital, Kottayam, were studied. Heart disease in this group was congenital or acquired in origin. Patients with isolated mitral valve prolapse and 12 women with heart disease who underwent therapeutic abortions were excluded.

\section{RESULTS}

In 100 mothers with heart disease, cardiac event occurred in 8\% pregnancies. It included 2 maternal deaths, 3 cardiac failures, 1 atrial fibrillation, 1 congestive cardiac failure with atrial fibrillation and 1 pulmonary embolism. NYHA class is a statistically significant predictor of cardiac events ( $p$ value- 0.001). Out of 28 pregnancies with left heart obstruction, 5 had a cardiac event and it was found to be significant ( $p$ value- 0.31). Previous history of cardiac events was present in 9 cases and $44.4 \%$ of these patients developed cardiac event in this pregnancy which was also significant ( $p$ value- 0.000 ). The requirement of cardiac medications and twin gestation were significant predictors of cardiac events ( $p$ value- 0.000).

\section{CONCLUSION}

Strict prenatal care and early risk stratification during pregnancy are important measures to improve the prognosis of pregnancy in women with heart disease.

\section{KEYWORDS}

Pregnancy, Heart Disease, Cardiac Events, Predictors.

HOW TO CITE THIS ARTICLE: Sapna S, Asha PS. Predictors of pregnancy related complications in women with heart disease. J. Evolution Med. Dent. Sci. 2018;7(10):1228-1231, DOI: 10.14260/jemds/2018/280

\section{BACKGROUND \\ $1 \%-3 \%$ of all pregnancies are complicated by maternal cardiac disease, an association that is responsible for about $20 \%$ of all maternal deaths. ${ }^{1}$ The incidence of cardiac disease during pregnancy has remained stable for many years since the decrease in the occurrence of rheumatic heart disease has been compensated by an increase of pregnancy in women with congenital heart disease. In developed countries, survival of new-borns affected by congenital heart disease is increasing as a result of complex surgical procedures performed in the first few years of life. ${ }^{2}$ As a result, the cardiologists and obstetricians are today facing an increasingly large group of pregnant women with surgically corrected congenital abnormalities. The obstetricians should have adequate information about cardiac diseases during pregnancy, so that they can function effectively as a member of the team taking care of the patient.}

'Financial or Other Competing Interest': None.

Submission 19-01-2018, Peer Review 14-02-2018,

Acceptance 21-02-2018, Published 05-03-2018.

Corresponding Author:

Dr. Asha P. S

Assistant Professor,

Department of Obstetrics and Gynaecology,

T. D. Medical College,

Alappuzha, Kerala.

E-mail: ashashihas@yahoo.com

DOI: $10.14260 /$ jemds $/ 2018 / 280$
To refine the risk stratification of women with heart disease so that they can receive appropriate obstetrical counselling and care, the frequency and predictors of pregnancy-related complications in women with heart disease who received their obstetrical care at Medical College, Kottayam, were evaluated.

\section{Aims and Objectives}

The objectives of the study were to comprehend the impact of heart disease during pregnancy, to study the cardiac complications in pregnant women with heart disease, to identify predictors of pregnancy related cardiac complications in women with heart disease and to assess the individual risk of each pregnant woman with heart disease.

\section{MATERIALS AND METHODS}

In this retrospective cohort study, the outcomes of pregnancies in 100 women with heart disease who received their obstetrical care at Medical College Hospital, Kottayam were studied. Heart disease in this group was congenital or acquired in origin. Patients with isolated mitral valve prolapse and 12 women with heart disease who underwent therapeutic abortions were excluded.

All pregnant women with heart disease receiving care in this hospital undergo standardised cardiac and obstetrical evaluations during their pregnancy. Definitions of predictors and outcomes were determined by consensus between a cardiologist and obstetrician before data collection. Data 
were obtained from independent review of health and clinical records. Baseline data were collected before review of outcomes and included maternal age, gestational age at 1st antenatal visit, New York Heart Association (NYHA) functional class at first antenatal visit, parity status, prior cardiac events (heart failure, transient ischaemic attack or stroke before present pregnancy), cardiac medications and heparin administered during pregnancy, prior cardiac surgical repair, evidence of central cyanosis and nature of the underlying cardiac lesion. ${ }^{3}$

Adverse events occurring during the antepartum, peripartum and postpartum periods were recorded. The outcomes were maternal cardiac events, defined as newonset heart failure (Pulmonary oedema by clinical assessment or chest $\mathrm{x}$-ray and requiring therapy), symptomatic tachyarrhythmia or bradyarrhythmia (Documented by ECG and requiring therapy), stroke or transient ischaemic attack of cardiac origin or cardiac death. ${ }^{4}$ This study procedure received approval from the Ethical Committee, Medical College, Kottayam.

Potential predictors of maternal cardiac complications included baseline NYHA functional class, prior corrective surgery, prior cardiac events and nature of underlying cardiac lesion. ${ }^{5}$ In view of the wide spectrum of cardiac lesions that were present as well as the presence of multiple types of lesions in a single patient, the mother's cardiac lesion in each pregnancy was classified as present or absent in each of the following pathophysiological categories: Left heart obstruction, right heart obstruction, left heart regurgitation and right heart regurgitation. The presence of obstruction, regurgitation and left ventricular systolic dysfunction was defined by validated transthoracic echocardiographic (Echo) indices obtained during the antepartum period. Valve areas used to define left heart obstruction were set at a level that could be haemodynamically significant in pregnancy.

\begin{tabular}{|c|c|}
\hline Category & Definition \\
\hline Shunt & $\begin{array}{c}\text { Atrial or ventricular septal defect, patent ductus } \\
\text { arteriosus or sinus of Valsalva to right ventricle } \\
\text { fistula }\end{array}$ \\
\hline $\begin{array}{c}\text { Left heart } \\
\text { obstruction }\end{array}$ & $\begin{array}{c}\text { Aortic valve area of }<1.5 \mathrm{~cm}^{2} \text {, mitral valve area } \\
\text { of }<2 \mathrm{~cm}^{2} \text { or left ventricular outflow tract peak } \\
\text { gradient of }>30 \mathrm{mmHg}\end{array}$ \\
\hline $\begin{array}{c}\text { Right heart } \\
\text { obstruction }\end{array}$ & $\begin{array}{c}\text { Tricuspid valve area of }<2 \mathrm{~cm}^{2} \text { or right } \\
\text { ventricular outflow tract peak gradient of }>25 \\
\text { mmHg }\end{array}$ \\
\hline $\begin{array}{c}\text { Left heart } \\
\text { regurgitation }\end{array}$ & $\begin{array}{c}\text { Moderate or severe regurgitation of aortic or } \\
\text { mitral valve }\end{array}$ \\
\hline $\begin{array}{c}\text { Right heart } \\
\text { regurgitation }\end{array}$ & $\begin{array}{c}\text { Moderate or severe regurgitation of pulmonic } \\
\text { or tricuspid valve }\end{array}$ \\
\hline $\begin{array}{c}\text { Pulmonary } \\
\text { hypertension }\end{array}$ & $\begin{array}{c}\text { Systolic pulmonary artery pressure exceeding } \\
50 \text { mmHg }\end{array}$ \\
\hline \multicolumn{2}{|c|}{ Table 1. Definitions of Pathophysiological Categories } \\
\hline
\end{tabular}

\section{Statistical Analysis}

Statistical analyses were performed for cardiac outcomes. Potential predictors of adverse outcomes in completed pregnancies were examined with $X^{2}$ test. A p-value $<0.05$ was considered to indicate statistical significance with $95 \%$ confidence interval. The data were analysed using statistical software SPSS version 16. The graph was constructed using Microsoft Excel software.

\section{RESULTS}

A total of 100 cases during the study period were included. A cardiac event complicated 8 completed pregnancies. It includes 2 maternal deaths, one on ninth postnatal day in a woman with hypertrophic obstructive cardiomyopathy and another in a woman with rheumatic mitral stenosis who died of congestive cardiac failure. Most cardiac events (75\%) occurred in the antepartum period and were either heart failure or cardiac arrhythmia (Fig. 1). The mean age was 26 years with a standard deviation of 2.5. The youngest patient was 18 years of age and the oldest was 39 years. There is no statistically significant association between maternal age and cardiac events ( $p$ value- 0.473). Most of the patients were nulliparous or para 1 . There were no grand multiparas in the study group. Parity was not a significant predictor of adverse cardiac event ( $p$ value- 0.198). Majority of the cases were class 1 or class 2 . No patient in the study group had class 4 heart disease. All the cases with class 3 heart disease were complicated by a cardiac event. NYHA class is a significant predictor of cardiac events (p value- 0.000) (Table 2). The aetiology of the maternal cardiac lesions was congenital in 48 cases and acquired in 52 pregnancies. Aetiological type of heart lesion was not a significant predictor of cardiac events ( $p$ value- .175). Right heart obstruction and Right heart regurgitation were present in 3 and 4 cases respectively. Right heart obstruction and Right heart regurgitation were not significant predictors of maternal cardiac events ( $p$ value0.369 and 0.298 respectively). Of the 28 pregnancies that occurred in women with left heart obstruction, 15 were in women with mitral stenosis and 5 were in those with aortic stenosis. In 8 pregnancies, the mother had combined aortic and mitral stenosis. The mean mitral valve area was $1.8 \pm 0.3$ $\mathrm{cm}^{2}$ (range, 1.2 to $2.0 \mathrm{~cm}^{2}$ ) in women with mitral stenosis. In those with aortic stenosis, the mean aortic valve area was $1.2 \pm 0.2 \mathrm{~cm}^{2}$ (Range, 0.7 to $1.5 \mathrm{~cm}^{2}$ ). Patients with aortic stenosis had valvular involvement, except for 1 patient with subaortic stenosis (with hypertrophic cardiomyopathy). The patient with Marfan syndrome had normal aortic root diameter. Left heart obstruction was a significant predictor of maternal cardiac events ( $p$ value- 0.023) (Table 3). Left heart regurgitation $(n=23)$ was not a significant predictor of maternal cardiac events ( $p$ value- 0.31). In 23 cases, the mother had undergone one or more of the following types of surgical repair before conception: (1) Closure of atrial septal defect $(n=9),(2)$ Closure of ventricular septal defect $(n=3)$, (3) Closed mitral valve commissurotomy $(n=3)$, (4) Balloon mitral valvuloplasty $(n=2),(5)$ Mitral valve replacement $(n=3),(6)$ Dual valve replacement $(n=1),(7)$ PDA ligation $(n=2)$. Prior surgical correction was not a significant predictor of maternal cardiac event ( $p$ value- 0.31 ). There was a previous history of cardiac events in 9 cases; $44.4 \%$ of these patients had cardiac complications in the current pregnancy. Prior cardiac events were a significant predictor of maternal cardiac events ( $p$ value- 0.00) (Table 4). The majority of patients did not require cardiac medications. The commonly used drugs included digoxin $(n=11)$, diuretics $(n=9)$, antiarrhythmics $(n=6)$ and anticoagulants $(n=7)$. The requirement of cardiac medications during pregnancy was statistically significant ( $\mathrm{p}$ value- 0.00 ) (Table 5 ). There were 2 cases of twin gestation. One among this was referred from a primary health centre as a case of cardiac failure complicating twin gestation. She was later diagnosed to have peripartum 
cardiomyopathy. The other case had intraoperative pulmonary oedema during caesarean section. Twin gestation was found to be a statistically significant predictor $(p-0.00)$ (Table 6).

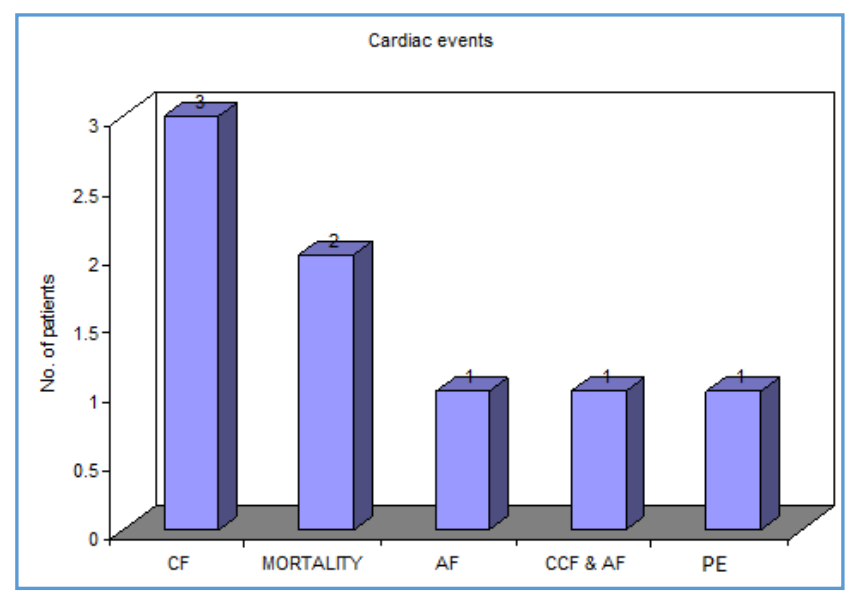

Figure 1. Cardiac Events

\begin{tabular}{|c|c|c|c|c|c|}
\hline \multirow{2}{*}{$\begin{array}{c}\text { NYHA } \\
\text { Class }\end{array}$} & \multicolumn{4}{|c|}{ Cardiac Events } & \multirow{2}{*}{ Total } \\
\cline { 2 - 5 } & \multicolumn{2}{|c|}{ Present } & \multicolumn{2}{c|}{ Absent } & \\
\cline { 2 - 5 } & Number & $\mathbf{\%}$ & Number & $\%$ & Number \\
\hline 1 & 0 & $.0 \%$ & 61 & $100.0 \%$ & 61 \\
\hline 2 & 4 & $11.4 \%$ & 31 & $88.6 \%$ & 35 \\
\hline 3 & 4 & $100.0 \%$ & 0 & $.0 \%$ & 4 \\
\hline Total & $\mathbf{8}$ & $\mathbf{8 . 0 \%}$ & $\mathbf{9 2}$ & $\mathbf{9 2 . 0} \%$ & $\mathbf{1 0 0}$ \\
\hline \multicolumn{6}{|c}{ Table 2. NYHA Class and Cardiac Events } \\
\hline
\end{tabular}

Using $\mathrm{X}^{2}=51.863 ; \mathrm{p}$ value $=0.000$. Result significant

\begin{tabular}{|c|c|c|c|c|c|}
\hline \multirow{2}{*}{$\begin{array}{c}\text { Lt. Heart } \\
\text { Obstruction }\end{array}$} & \multicolumn{4}{|c|}{ Cardiac Events } & \multirow{2}{*}{ Total } \\
\cline { 2 - 5 } & \multicolumn{2}{|c|}{ Present } & \multicolumn{2}{c|}{ Absent } & \\
\cline { 2 - 5 } & No. & $\mathbf{\%}$ & No. & $\mathbf{\%}$ & No. \\
\hline Present & 5 & $17.9 \%$ & 23 & $82.1 \%$ & 28 \\
\hline Absent & 3 & $4.2 \%$ & 69 & $95.8 \%$ & 72 \\
\hline Total & $\mathbf{8}$ & $\mathbf{8 . 0} \%$ & $\mathbf{9 2}$ & $\mathbf{9 2 . 0} \%$ & $\mathbf{1 0 0}$ \\
\hline Table 3. Left Heart Obstruction and Cardiac Events \\
\hline
\end{tabular}

Using $\mathrm{X}^{2}=5.134 ; \mathrm{p}$ value $=0.023$. Result significant.

\begin{tabular}{|c|c|c|c|c|c|}
\hline \multirow{3}{*}{$\begin{array}{c}\text { Prior Cardiac } \\
\text { Events }\end{array}$} & \multicolumn{4}{|c|}{ Cardiac Events } & \multirow{3}{*}{$\begin{array}{c}\text { Total } \\
\text { No. }\end{array}$} \\
\hline & \multicolumn{2}{|c|}{ Present } & \multicolumn{2}{|c|}{ Absent } & \\
\hline & No. & $\%$ & No. & $\%$ & \\
\hline Present & 4 & $44.4 \%$ & 5 & $55.6 \%$ & 9 \\
\hline Absent & 4 & $4.4 \%$ & 87 & $95.6 \%$ & 91 \\
\hline Total & 8 & $8.0 \%$ & 92 & $92.0 \%$ & 100 \\
\hline
\end{tabular}

Using $\mathrm{X}^{2}=17.848 ; \mathrm{p}$ value $=0.000$. Result significant

\begin{tabular}{|c|c|c|c|c|c|}
\hline \multirow{2}{*}{$\begin{array}{c}\text { Cardiac } \\
\text { Medications }\end{array}$} & \multicolumn{4}{|c|}{ Cardiac Events } & \multirow{2}{*}{ Total } \\
\cline { 2 - 6 } & \multicolumn{2}{|c|}{ Present } & \multicolumn{2}{c|}{ Absent } & \\
\cline { 2 - 6 } & No. & $\%$ & No. & $\%$ & No. \\
\hline Present & 7 & $33.3 \%$ & 14 & $66.7 \%$ & 21 \\
\hline Absent & 1 & $1.3 \%$ & 78 & $98.7 \%$ & 79 \\
\hline Total & $\mathbf{8}$ & $\mathbf{8 . 0 \%}$ & $\mathbf{9 2}$ & $\mathbf{9 2 . 0} \%$ & $\mathbf{1 0 0}$ \\
\hline Table 5. Cardiac Medications and Cardiac Events \\
\hline
\end{tabular}

Using $\mathrm{X}^{2}=23.179 ; \mathrm{p}$ value $=0.000$. Result significant.

\begin{tabular}{|c|c|c|c|c|c|}
\hline \multirow{2}{*}{$\begin{array}{c}\text { Twin } \\
\text { Gestation }\end{array}$} & \multicolumn{4}{|c|}{ Cardiac Events } & \multirow{2}{*}{ Total } \\
\cline { 2 - 5 } & \multicolumn{2}{|c|}{ Present } & \multicolumn{2}{c|}{ Absent } & \\
\cline { 2 - 5 } & Number & $\mathbf{\%}$ & Number & $\%$ & Number \\
\hline Present & 2 & $100.0 \%$ & 0 & $.0 \%$ & 2 \\
\hline Absent & 6 & $6.1 \%$ & 92 & $93.9 \%$ & 98 \\
\hline Total & $\mathbf{8}$ & $\mathbf{8 . 0} \%$ & $\mathbf{9 2}$ & $\mathbf{9 2 . 0} \%$ & $\mathbf{1 0 0}$ \\
\hline \multicolumn{6}{|c|}{ Table 6. Twin Gestation and Cardiac Events } \\
\hline
\end{tabular}

Using $\mathrm{X}^{2}=23.469 ; \mathrm{p}$ value $=0.000$. Result significant.

\section{DISCUSSION}

The study provides an assessment of maternal cardiac risk associated with pregnant women with heart disease who are receiving comprehensive antenatal care. The cardiac event rate in the present study (8\%) is lower than that reported in previous studies. In a prospective multicentre study of pregnancy outcomes in women with heart disease, Siu et al ${ }^{5}$ reported a $13 \%$ incidence of primary cardiac events. This lower event rate may be explained in part by differences in study populations. As in the present study, the most common cardiac complications have been found to be congestive heart failure.5,7,8 Most cardiac events (75\%) occurred in the antepartum period and the results are comparable to $82 \%$ obtained by Siu SC et al. ${ }^{5}$ However, the high maternal mortality rate of $2 \%$ is not comparable with western studies. The low maternal mortality observed in those studies may be due to greater vigilance in the care of pregnant women with heart disease or the avoidance of pregnancy by women in higher risk groups.

Poor NYHA class, left heart obstruction, prior arrhythmia and prior heart failure/ stroke have been previously identified as risk factors for maternal cardiac events.5,9,10,11 The present study extends the results of previous studies by quantifying these risks prospectively in the population group studied. The present study also quantified the association of left heart obstruction and history of prior cardiac events with the risk of maternal cardiac complications during pregnancy. The association between left heart obstruction and cardiac events is probably mediated by the changes in cardiac output, heart rate and systemic vascular resistance during pregnancy.

The requirement of cardiac medications during pregnancy correlated well with poor functional class and was a significant predictor of maternal cardiac events.

In contrast to previous studies by Shime J et $\mathrm{al}^{9}{ }^{9}$ Whitemore $\mathrm{R}$ et $\mathrm{al}^{10}$ and McFaul PB et al,11 prior cardiac surgery was not associated with complications in this study. The results are comparable to study by Siu SC et al.3,4,5 Operative status was not predictive of complications in this study, possibly due to the absence of residual disease.

Maternal age, parity, aetiological type of lesion, right heart regurgitation, right heart obstruction and left heart regurgitation were not significant predictors. The results are comparable to the observations by Siu SC et al. ${ }^{4}$

In contrast to previous study by Siu SC et al, ${ }^{5}$ the present study showed a strong predictive role for multiple gestation in the development of maternal cardiac complications, $(p=0.00)$. Multiple pregnancies are characterised by marked variations in stroke volume and cardiac output during the antepartum period and at the time of labour and after delivery as compared to singleton pregnancies. This could lead to maternal cardiac decompensation and increased rate of complications. 
However, the current study failed to substantiate the previously reported predictive role of cyanosis and pulmonary artery hypertension on cardiac outcome due to the lack of cases. There were no women with cyanosis or Eisenmenger syndrome in this study, probably because the patients with diseases were not allowed to continue pregnancy.

In this study, some categories may not be predictive of complications because of small numbers. Also, a larger patient sample may allow the identification of additional risk factors.

\section{CONCLUSION}

1. Pregnancy in women with heart disease is still associated with considerable morbidity and mortality rates, which strongly correlate to maternal underlying disease.

2. Maternal cardiac complications occurred in $8 \%$ of pregnancies in women with heart disease and the most common complication was congestive cardiac failure.

3. The predictors of maternal cardiac complications were poor functional class, left heart obstruction, prior cardiac events, twin gestation and the requirement of cardiac medications during pregnancy.

4. Maternal age, parity and aetiological type of lesion were not significant predictors of maternal cardiac events.

5. Strict prenatal care and early risk stratification during gestation are fundamental measures to improve the prognosis of pregnancy in women with heart disease.

\section{REFERENCES}

[1] Simpson LL. Maternal cardiac disease: update for the clinician. Obstet Gynecol 2012;119(2 Pt 1):345-59.

[2] Engelfriet P, Boersma E, Oechslin E, et al. The spectrum of adult congenital heart disease in Europe: morbidity and mortality in a 5 year follow-up period. The euro heart survey on adult congenital heart disease. Eur Heart J 2005;26(21):2325-33.
[3] Siu SC, Grewal J. Comprehensive predictor of cardiac outcome in pregnant women with heart disease. Circulation 2017; 136:A15606.

[4] Siu SC, Sermer M, Colman JM, et al. Prospective mutlicentric study of pregnancy outcomes in women with heart disease. Circulation 2001;104(5):515-21.

[5] Siu SC, Sermer M, Harrison DA, et al. Risk and predictors of pregnancy-related complications in women with heart disease. Circulation 1997;96(9):2789-94.

[6] Elkayam U. Pregnancy and cardiovascular diseases in Braunwald's heart disease. $6^{\text {th }}$ edn. Saunders WB, 2001:2172-91.

[7] Khairy P, Ouyang DW, Fernandes SM, et al. Pregnancy outcomes in women with congenital heart disease. Circulation 2006;113(4):517-24.

[8] Avila WS, Rossi EG, Ramires JA, et al. Pregnancy in patients with heart disease: experience with 1,000 cases. Clin Cardiol 2003;26(3):135-42.

[9] Shime J, Mocarski EJ, Hastings D, et al. Congenital heart disease in pregnancy: short-and long-term implications. Am J Obstet Gynecol 1987;156(2):31322.

[10] Whitemore R, Hobbins JC, Engle MA. Pregnancy and its outcome in women with and without surgical treatment of congenital heart disease. Am J Cardiol 1982;50(3):641-51.

[11] McFaul PB, Dornan JC, Lamki H, et al. Pregnancy complicated by maternal heart disease: a review of 519 women. Br J Obstet Gynaecol 1988;95(9):861-7. 